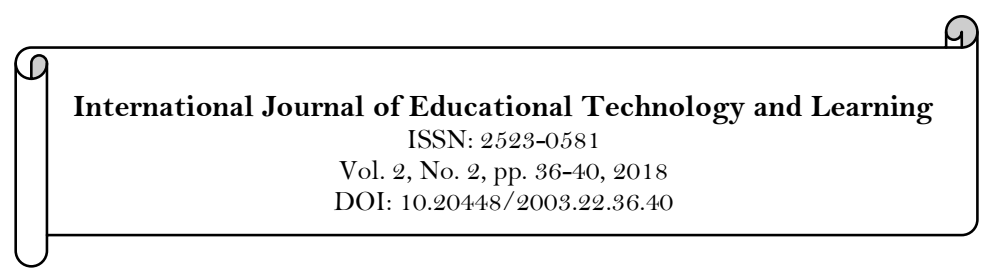

\title{
Hour of Code and its Cultural Educative Impact on Preschool, Basic Education and Middle School
}

\author{
Ma del Carmen Nolasco ${ }^{1}$ \\ ${ }^{1}$ Department of Basic Sciences in the University Center of the Ciénega, Mexico. \\ Email:mcns08@gmail.com
}

\begin{abstract}
At the present time, information and communication technologies integrate learning through a ubiquitous formation, which permits access to formative resources. Hour of Code is a global movement that is currently exerting a great impact in more than 180 countries, as well as being a spectacular development of opportunities in distinct activities and projects according to the age of the participants. The fundamental objective of this great event is to increase the growth of the use of the program within the educative ambit to foster creativity and logical thinking, highlighting that no experience is needed to learn to program and to develop problemsolving skills. For student of basic education, the term "program" implies a series of codes that makes them think about a world of ideas, but one that they consider to be difficult to achieve on inserting them into their computer. This is due to lack of knowledge on programming. In the face of this context, the Centro Universitario de la Ciénega (CUCiénega) in Mexico has generated the idea of providing students from preschool and basic education a first contact with the world of programming. This is a studentcentered interdisciplinary proposal that encompasses the development of cognitive skills at all learning levels; the purpose of the present article was to orient reflection concerning the development of thinking and creativity skills, conceiving of these as revitalizing learning factors.
\end{abstract}

\author{
Keywords: \\ Students \\ Programming \\ Students-Instructor \\ Technologies \\ Knowledge. \\ Licensed: \\ This work is licensed under a \\ Creative Commons Attribution \\ 4.0 License. \\ Publisher: \\ Scientific Publishing Institute
}

\section{Introduction}

At the present time, information and communication technologies integrate learning through a ubiquitous formation, which permits access to formative resources.

Hour of Code is a global movement that is currently exerting a great impact in more than 180 countries, as well as being a spectacular development of opportunities in distinct activities and projects according to the age of the participants. The fundamental objective of this great event is to increase the growth of the use of the program within the educative ambit to foster creativity and logical thinking, highlighting that no experience is needed to learn to program and to develop problem-solving skills.

For student of basic education, the term "program" implies a series of codes that makes them think about a world of ideas, but one that they consider to be difficult to achieve on inserting them into their computer. This is due to lack of knowledge on programming.

In the face of this context, the Centro Universitario de la Ciénega (CUCiénega) in Mexico has generated the idea of providing students from preschool and basic education a first contact with the world of programming. This is a student-centered interdisciplinary proposal that encompasses the development of cognitive skills at all learning levels; the purpose of the present article was to orient reflection concerning the development of thinking and creativity skills, conceiving of these as revitalizing learning factors.

The manner in which CUCiénaga has done its part in carrying out the Hour of Code project, with the objective of promotion and making inroads in children in preschool, primary, and basic education in the knowledge of the computer sciences, stimulating creativity and logic, starting with learning liable to be directed toward the development of thinking skills, mediated by teaching strategies endorsing the evolution of intrinsic thought. 
The purpose of this project was to show students that prior knowledge is not required, nor the possession of special abilities or skills, in order to learn programming. Students must simply change the perspective that they have about programming, and we must demonstrate to them that programming is not as difficult as they think it is.

\section{Educative Importance}

During the upsurge of the digital revolution, the educative environment has had to effect great changes in education; it has had to incorporate the use of the computer in schools as support for the activities of the students and of the teaching staff. Nonetheless, and although the tools that Information Technologies (IT) offer can be learning triggers, much still remains for us to "learn to learn" to be facilitators. Therefore, we are not taking advantage of IT in schools as we should be; thus, Hour of Code has been the driving component for students to enjoy technology in a fun and simultaneously educative manner, generating knowledge in this fashion.

One of the most important tasks of educators is that of aiding in the construction of a social movement that provides a space for an inclusive and dynamic public educative system in the knowledge society (Hargreaves \& Fink, 2006)

Hour of Code offers activities in different areas and multiple hardware needs to students at any level. In Figure 1, we present an illustration of this global movement.

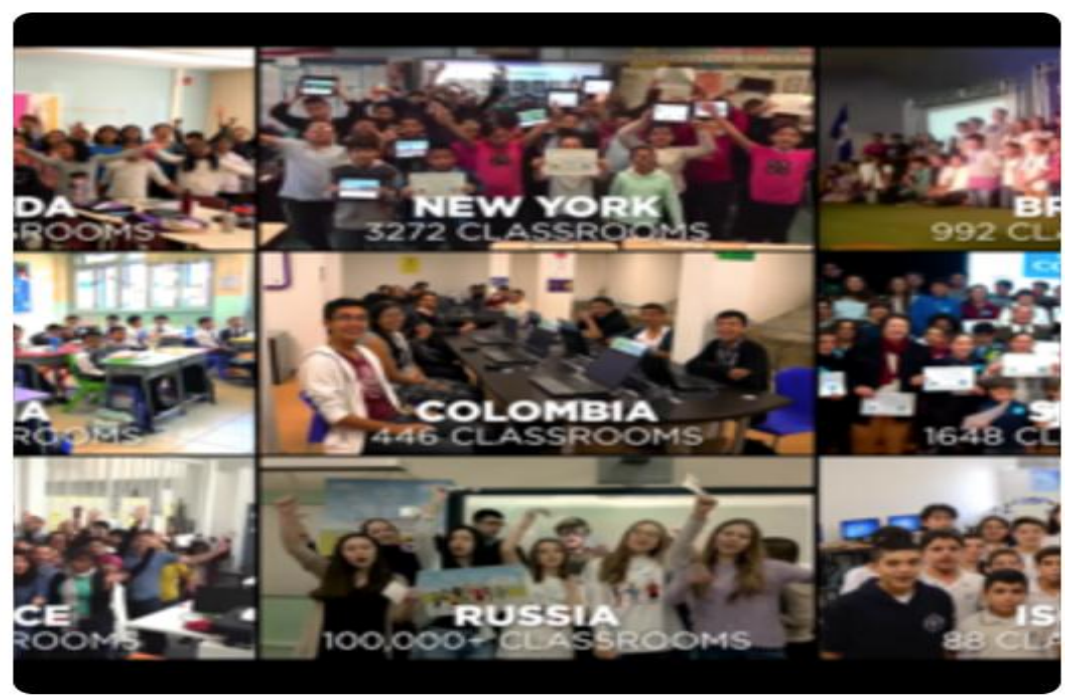

Source: https://hourofcode.com

Approximately 360 preschool, primary, secondary, telesecondary, and Colegio de Bachilleres del Estado de Jalisco (COBAEJ, Guadalajara, Mexico) students participated; $94 \%$ had utilized computers in order to access Paint, word processing, Excel, PowerPoint, social networks or, simply, to play, and 6\%, that is, 20 students of the 360 participants in Hour of Code had already engaged in programming during their undergraduate university studies Figure 2.

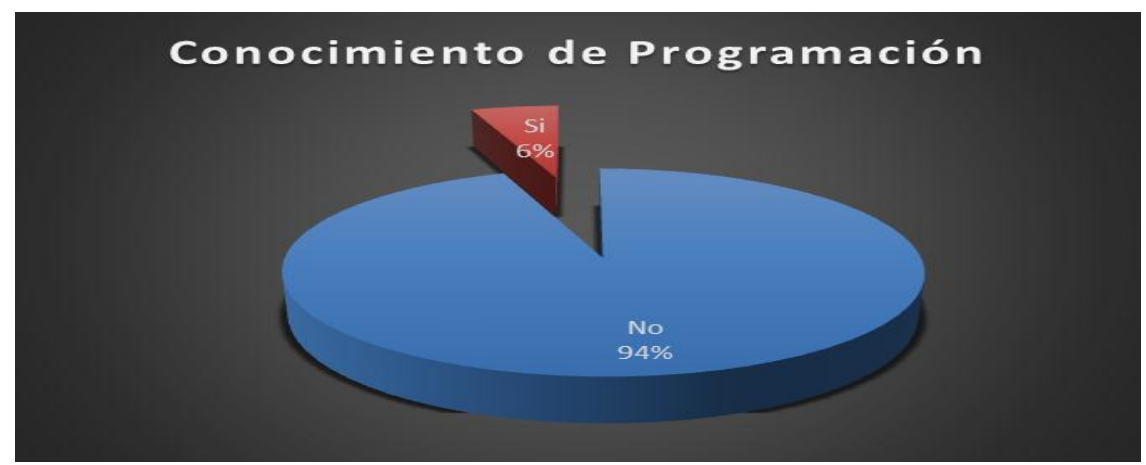

Figure-2. Participants with programming knowledge. Source: results of surveys made to participants.

The group of university students who provided support in the project were concerned at the beginning. It would appear not to be easy to be in front of a group and to share knowledge in such a way that the receivers 
absorb the information rapidly and simply to comply with the objective. However, once these university students were with the group assigned to them, it was incredibly gratifying to observe their enthusiasm for sharing the knowledges that they obtained during their university studies.

These university students said the following: "Knowing how to program makes us feel great, sharing our knowledge and being able to capture the interest of the participants has made us believe in ourselves", and "It gives us great satisfaction to realize that we can share, with little ones from the age of 4 years, primary school students, secondary-school adolescents, the knowledges that we acquired during our university years". This is how the university students who functioned as instructors in each of the workshops offered in Hour of Code felt.

During the workshops, the students participating in this event exhibited true interest in carrying out the activities and were observed to be really enthusiastic when they made their game work. This was a challenge for them in that it was something new, but above all, somehting very much in vogue at present, i.e., the mobile devices as well as the computers. What is it that attracts the most attention today in children and young people? Without doubt, video games.

Solving this type of problem in computers motivates the human mind and teaches us a novel way of seeking solutions, here, logical thinking. The programming that is utilized in this global movement is conducted by means of blocks rather than by textual commands. The advantage is that a logical focus is generated in the construction of algorithms and there is a minimal amount of syntactic and compilation errors.

This type of visual programming is very useful for urging students from an early age to program, in such a way that they develop logical thought, improving their cognitive and creative skills.

The workshops offered to the students participating in this event were given through languages by blocks, a language that has left to one side the abstract, in order to be visual. To what do we make reference to a visual language? A visual language is one that provides us with a series of qualities that execute actions through instructions indicated by the user, for example, make it so that each time the user presses the spacer key the personage jumps, bends over, or shoots. This action attracts the attention of the students, because it seems incredible to them that they were able to do this: they thought that it would be difficult, even to move the keyboard arrows, they were enthusiastic, it was a transformative experience.

Some of the programming languages utilized are Scratch, which is oriented toward the development of small animations, applications, and games. It has been developed by and for children and the educative environment and is free of charge Figure 3.

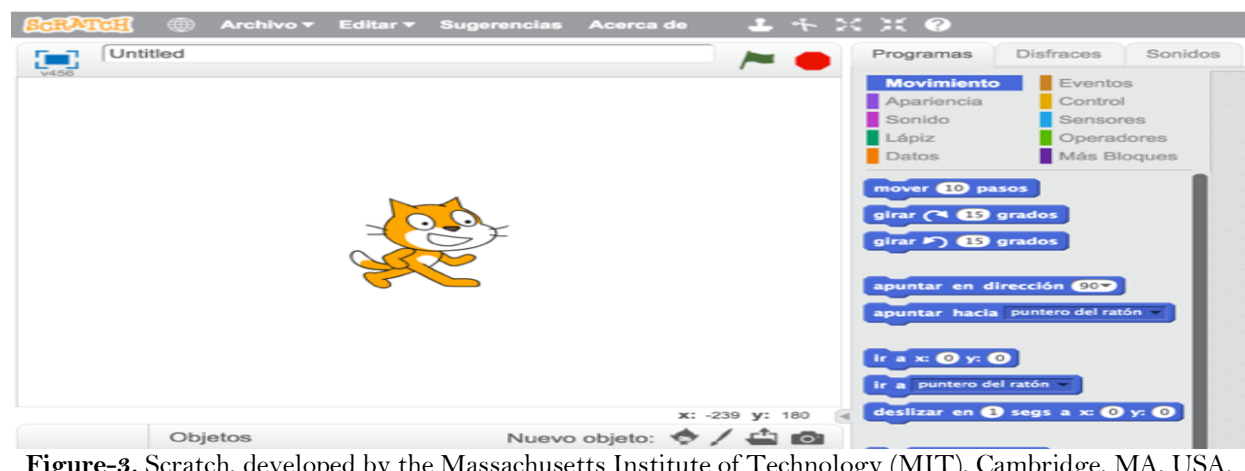

Figure-3. Scratch, developed by the Massachusetts Institute of Technology (MIT), Cambridge, MA, USA. Source: https://scratch.mit.edu/.

Another Is Google Blockly, also oriented toward children and young people. Users can drag blocks to build an application as it they were fitting pieces into a puzzle Figure 4. And better yet, no writing is necessary

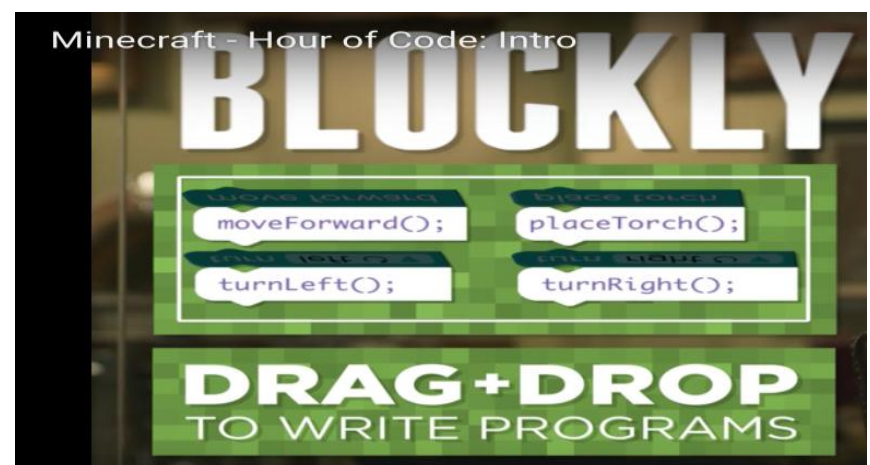

Figure-4. Google Blockly.

Source: https://studio.code.org/s/mc/stage/1/puzzle/1. 
Blockly does not involve the placement of blocks, but instead, using the least amount of these, that is, having to repeat the same instruction the least amount of times in achieving the proposed objective. Everything evolves in parallel with the technologies; programming languages are more similar to human language. Seeing this helped many students to understand and to reflect on that writing a code was not as difficult as they had originally thought.

This experience of motivating young people toward programming was a great satisfaction. From the project's initiation, it comprised an enormous challenge: in assigning the Problem-Solving Software Engineering Seminar, we took on the task of proposing this project with the purpose of that the students participating in this assignment would develop the competence of "self-managed" learning" and the application of "solution-development" strategies.

David H. Jonassen sustains that the support that the technologies should contribute to learning should not intend to provide instruction to the students, but instead, should act as tools for building learning, in order for students to learn with, not from, them (Jonassen, 2002).

Transformative, satisfactory, and intense, this experience has been all of these things. I began organizing a project of social sensitivity, which involved interaction with the region's student communities, as well as the creation of special activities in which university students could aid in the development of social activities for children, adolescents, and young people from preschools and from primary, secondary, and preparatory schools. According to Díazs (2005) "Only the link-up of learning and teaching methodology will permit the teaching staff to establish different learning strategies, with the sole condition of seeking to foster conditions of learning, another fundamental principle in the field of Didactics ".

The university students assumed the role of instructors who, at the beginning of the project and to even to the very day that it began, were afraid, did not believe in their abilities: all were insecure in terms of being able to share their learnings with the student communities with which they would come to participate.

But the day came, the long-awaited day, accompanied by nerves, fear, and insecurity, when the university students had the little ones in a classroom awaiting instructions for starting to work with the activities that they themselves (the university students) had planned for working with the little ones. The latter turned out simply brilliantly, proving to be an excellent and meaningful way to recognize what we can do, exerting a positive and significant impact on the participating communities, and on us, our Institution, and our university students.

David H. Jonassen sustained that "mindtools" are computer applications that, when utilized by students to represent what they know, necessarily involve these students in critical thought regarding the content that they are studying Jonassens and Reeves (1996).

The university students who served as facilitator in this project proposed a real project, in addition to creating their own strategies for solutions. This rendered it feasible for the student to demonstrate, by means of their projects, the skills and knowledges that permit them to analyze and make viable their informatics solution.

A project that we knew was going to be a full-blown challenge.

The experiences have been highly gratifying, in that it has been appreciated that children and young people interact to the degree that they develop the activities, formulating multiple questions and involving themselves in an active and creative way.

The following is what everyone should seek in ALL educative programs, in all the lessons of any subject, of any language in classrooms: a sense of achievement, or success, empowering students to achieve their personal excellence.

Professors who employ CIT do so primarily to support personal work (the search for information, use of the word processor, for the preparation of classes) and, and to a much lesser extent, for the teaching task per se, such as the use of educative software, presentations and simulations, the promotion of teamwork, communication with and among students, or the management of Communications and Information Technologies (CIT)-supported learning projects (Díaz, 2008).

At present in education, programs are being implemented that are being applied in classrooms. Thus, students propose novel ideas, supporting themselves with the technology-at-hand, generating knowledge within a formal context through basic, high-school, and higher education.

Notwithstanding this, there are other knowledge-acquisition forms are developed during the course of each individual in his/her learning process. This has to do with knowledge acquired through the familial and social environments, but above all, is due to accumulated experience and constant observation.

\section{Conclusions}

An empirical model was able to be established, through observation, by classifying into categories the different groups that participated in Hour of Code, that explains how preschool, primary, and secondary school students possess the capacity to appropriate for themselves in a meaningful manner the concepts of logicomathematical thought in an educative environment and to apply them in the context where it is found.

The environment of Scratch furnishes an ambience of flexible learning that is learner-friendly and fun for all who are interested in programming, from preschool up through the levels of higher education. The way 
that the participants thought about the solution of the dynamic activities that they were executing, devised by the instructors-facilitators, was a dynamic and simple process see Figure 5.

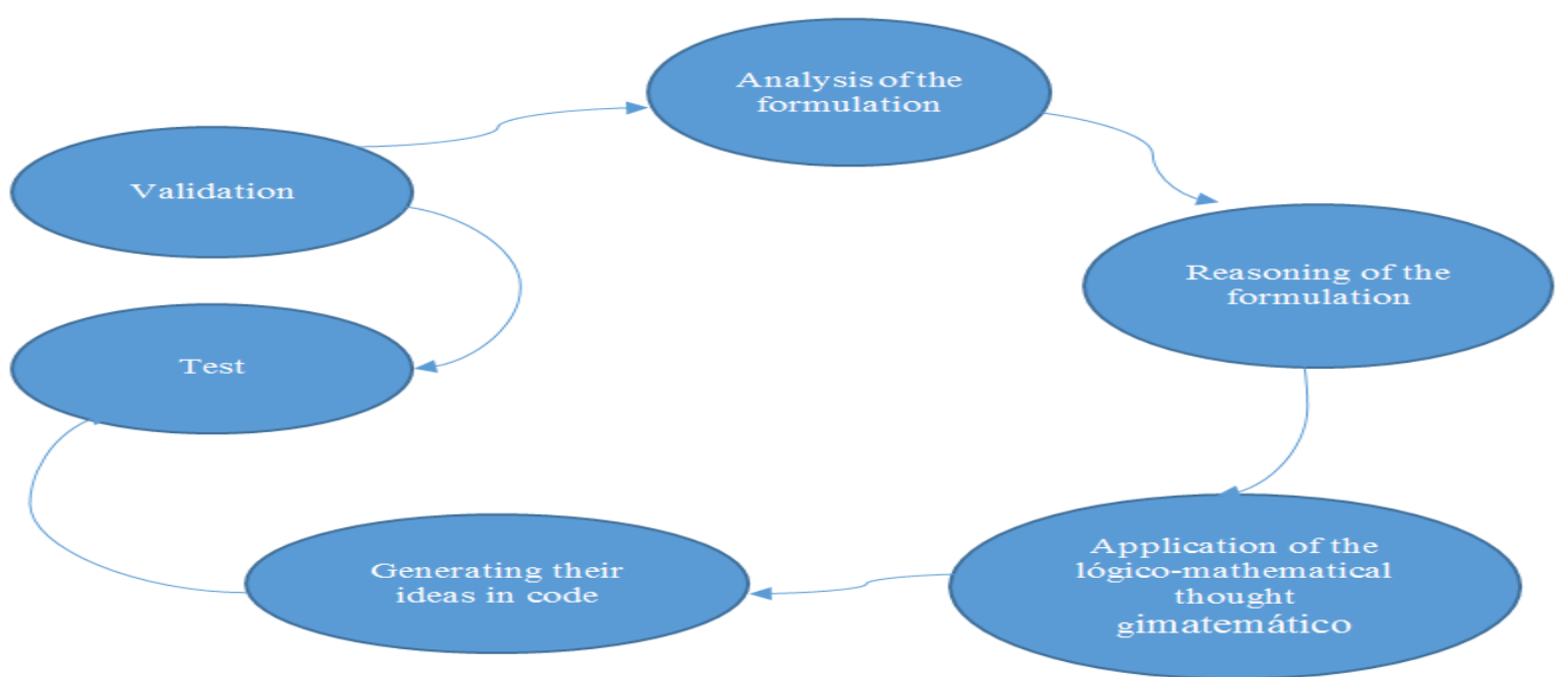

Figure-5. Dynamic and simple process.

Logico-mathematical knowledge "arises from a reflexive abstraction". The latter is due to that this knowledge is not observable and that it is the child who constructs it in his/her mind through relationships with objects, the latter developing from the most simple to the most complex. This entertains the particularity that the knowledge acquired, once processed, is not forgotten, because the experience does not originate from the objects but rather, from the child's action upon the objects themselves (Dongo, 2008).

\section{References}

Díaz, B. F. (2008). Education and new information technologies: Towards an innovative educational paradigm? Synectics, Electronic Journal of Education, Without Month, 1-15.

Díazs, B. Á. (2005). The professor of higher education confronts the demands of the new educational debates. Perfiles Educativos, 27(108), 9-30.

Dongo, M. A. O. (2008). Piaget's theory of learning and its consequences for educational praxis. IIPSI Magazine, 11, 167181.

Hargreaves, A., \& Fink, D. (2006). Strategies for change and improvement in education characterized by their relevance, dissemination and continuity over time. Education Magazine, 339(84), 43-58.

Jonassen, D. (2002). Computers as tools of the mind. Retrieved from http://eduteka.icesi.edu.co/articulos/Tema12. [Downloaded: 03/03/2017].

Jonassens, D. H., \& Reeves, T. C. (1996). Learning with technology: using computers as cognitive tools. In: D.H. Jonassen (Editor), Handbook of Research for Educational Communications and Technology (pp. 693-719). New York: Macmillan. 